\title{
Comparison Between Mercury and Liquid Crystal Forehead Thermometers for Measurment of Body Temperature
}

\author{
Rahman $\mathrm{N}^{1}$, Kasem $\mathrm{FB}^{2}$, Islam $\mathrm{MR}^{3}$, Islam $\mathrm{MR}^{4}$, Sultana $\mathrm{R}^{5}$, Matin $\mathrm{A}^{6}$
}

\begin{abstract}
Background: Body temperature is a measure of the body's ability to generate and get rid of heat. For recording of body temperature several different types of thermometers are available, such as mercury thermometers, digital thermometer, liquid crystal forehead thermometer, and infrared tympanic thermometer are used. The accuracy of the device is to record and grade temperature is uncertain. Objective: The study was carried out the recordings of normal body temperature using liquid crystal forehead thermometer and compare with gold standard oral mercury thermometer. Methodology: Simultaneous recording were made using the two devise in randomly enrolled 150 apparently healthy medical student eighteen (18) to twenty (20) years age of either sex. Written \& verbal consent was taken from the students without any coercion. Oraltemperature was recorded with Chinese made mercury thermometer and the forehead temperature was recorded using liquid crystal (Boots, UK) thermometer. Results: No statistical significant difference existed between the recordings of two devices. The mean difference was 0.8 degree. Liquid crystal forehead thermometer recorded higher temperatures. Both the devices recorded temperature within normal range. Conclusions: Sensitivity of liquid-crystal thermometer to detect body temperature is comparable with that of mercury thermometer. It is a good device for home use but health providers should not use it. Mercury thermometer remains the gold standard.
\end{abstract}

Key words: Body temperature, Mercury thermometer, liquid-crystal thermometer, comparison

\section{Introduction}

Body temperature is the result of the body's ability to generate and get rid of heat. The normal physiology is to keep body temperature within a narrow safe range in spite of large variations in environmental temperatures ${ }^{1,2}$.

In 1868 Carl Wunderlich laid down the position that the normal temperature was a sign of health while mobility of temperature indicates disease 2 . Human body temperature is maintained between $97^{\circ}-99^{\circ} \mathrm{F}\left(36^{\circ}-37.5^{\circ} \mathrm{C}\right)$. For recording of body temperature several different types of thermometers are available, such as mercury thermometers, digital thermometer and infrared tympanic thermometer. Now a day's liquid crystal forehead thermometer has made temperature recording seemingly very easy ${ }^{2,3}$.

The standard method of measuring body temperature is to use a clinical thermometer made up glass filled up with mercury which has Fahrenheit and Centigrade scale. Fahrenheit scale extends from $94^{\circ}-108^{\circ} \mathrm{F}$ with and arrow at $98.6^{\circ} \mathrm{F}$ to indicate the mean value of body temperature. Centigrade scale extends from $35^{\circ}-42^{\circ} \mathrm{C}$ with an arrow at $37^{\circ} \mathrm{C}$ which indicate normal body temperature ${ }^{2,3,4}$.
To record body temperature the clinical thermometer is placed under the tongue, in the armpit, in the groin but to record core temperature special type of clinical thermometer is inserted into the rectum. The reading obtained in the armpit is about $0.5^{\circ} \mathrm{F}$ lower than that in the mouth. 2 Digital thermometer is used to take oral temperature. It is a small hand held device with a "window" showing the temperature in number. Most digital thermometer are easy to use and measure body temperature within seconds ${ }^{3,5}$. Low battery is a problem for digital thermometer.

The introduction of liquid crystal forehead thermometer has made temperature recording seemingly very easy. A liquid crystal thermometer contains heat sensitive liquid crystals in a plastic strip and changes its color on different temperatures.

The temperature can be measured within 15 seconds of placing on the forehead ${ }^{3,6,7}$. It is safer and comfortable than mercury in glass thermometer. These have an additional advantage of minimizing the risk of cross infection from one subject to another. Body temperature is checked to detect fever or hypothermia ${ }^{3,6,8}$.

1. Dr. Nilufar Rahman, Professor, Department of Physiology, Shaheed Suhrawardy Medical College, Dhaka

2. Dr. Fouzia Binte Kasem, Associate Professor, Department of Physiology, Shaheed Suhrawardy Medical College, Dhaka

3. Dr. Md. Reazul Islam, Trainee Medical Officer, Dhaka National Medical College \& Hospital, Dhaka

4. Dr. Md. Rafiqul Islam, Associate Professor, Department of Pediatrics, Shaheed Suhrawardy Medical College and Hospital, Dhaka

5. Dr. Rezina Sultana, Associate Professor, Department of Physiology, Dhaka Medical College, Dhaka

6. Dr. Abdul Matin, Assistant Professor, Department of Pediatric, Shaheed Suhrawardy Medical College and Hospital, Dhaka

Correspondence :

Dr. Nilufar Rahman, Professor, Department of Physiology, Shaheed Suhrawardy Medical College, Dhaka -1207, Bangladesh;

Email: jkabir@bol-online.com; Cell no.: +8801818362673 
An increasing trend is seen in health providers and general population to use forehead thermometer; however, the accuracy of the device is to record and grade the temperature is uncertain. Some investigators in different countries observed that the mercury thermometer is more accurate than other thermometers ${ }^{7,8}$. So far there is no available data in this country. Therefore, the present study was designed to compare the recordings of body temperature using oral mercury thermometer and liquid crystal forehead thermometer.

\section{Methodology}

This cross-sectional study was conducted in the Department of Physiology at Shaheed Shurawardy Medical College and Dhaka Medical College, Dhaka from November 2008 to December 2008. All first year MBBS medical students at the age of eighteen (18) to twenty (20) years of either sex were selected randomly by selecting every third student. The students were explained the purpose of the study. Both the written \& verbal consent was taken from the students without any coercion. When students did not give consent for any reason next student was selected. The inclusion criteria were apparently healthy student without the history of fever or respiratory tract infection or any acute as well as chronic illnesses. The exclusion criteria were aged below 18 years and exceeding 20 years, suffering from fever, history of any type of infection, history of any cardiac diseases or peripheral vascular diseases, history of hyperthyroidism hypothyroidism. Oral-temperature was recorded with Chinese made mercury thermometer and the forehead temperature was recorded using liquid crystal. (Boots, UK) thermometer' It was ensured that the subject had not taken cold or hot drink during the last 30 minutes and they were sit in ambient room temperature for the last one hour. At the time of recording forehead temperature the forehead skin is dry and clean.

\section{Results}

A total number of one hundred \& fifty (150) first year MBBS medical student eighteen (18) to twenty (20) years age of either sex were selected randomly by selecting every third student.

Table 1: Distribution of Study population according to Age

\begin{tabular}{lc}
\hline Mean age \pm SD (years) & Range (years) \\
\hline $18.5 \pm 2.89$ & $16-20$ \\
\hline
\end{tabular}

Mean values of temperature from both the methods were calculated and compared with each other to determine the level of significance by applying student's't' test. Results are summarized in (Table 1).

Table 2: Distribution of Study population according to sex

\begin{tabular}{lcc}
\hline Sex & Frequency & Percentage \\
\hline Male & 79 & 52.7 \\
Female & 71 & 47.3 \\
Total & $\mathbf{1 5 0}$ & $\mathbf{1 0 0 . 0}$ \\
\hline
\end{tabular}

Table 3: Comparison of body temperature recorded with Mercury thermometer \& liquid-crystal thermometer

\begin{tabular}{lll}
\hline $\begin{array}{l}\text { Types of } \\
\text { Thermometer }\end{array}$ & $\begin{array}{l}\text { Temparature } \\
(\text { Mean } \pm \text { SD) }\end{array}$ & \\
\hline Mercury thermometer & $97.8 \pm 1.18$ & $<0.53^{*}$ \\
Liquid-crystal thermometers & $98.6 \pm 1.18$ & \\
\hline
\end{tabular}

- Independent $t$ test has been done to see the association.

- P value not significant $(>0.05)$

\section{Discussion}

Temperature recording is an essential step in the evaluation of both indoor and outdoor patients throughout the world. Patients presenting with high grade fever needs an urgent diagnostic evaluation, leading to prompt therapeutic intervention $^{3}$. Thus grading of temperature has clinical implications. Mercury thermometers are widely used for such purposes.

Introduction of liquid-crystal thermometers has made temperature recording easy and safe but their accuracy has been questioned ${ }^{4-6}$. One study reported by Board et $\mathrm{al}^{7}$ suggested that not only did the disposable thermometer records quicker than the mercury thermometer but it was as accurate.

Analysis of this data elucidates that liquid-crystal thermometers are equally good in screening as compared to mercury thermometers.

\section{Conclusion}

From this study it has been concluded that the sensitivity of liquid-crystal thermometer to detect temperature is comparable with that of mercury thermometer. It is a good device for home use but health providers should not use it. Mercury thermometer remains the gold standard.

\section{References}

1. McGrew N, Roderick E. Encyclopedia of Medical History, McGraw Hill, New York. 1985:73-74

2. Green JH. An introduction to Human Physiology.4th Edition, Oxford University Press. 1984:149-50

3. Greene HL, Glassock RJ, Kelley MA. Introduction to Clinical Medicine, B.C.Decker lnc. Hamilton. 1991: P 149

4. Kongpanichkul A, Bunjongpak S. A comparative study on accuracy of liquid-crystal forehead' digital electronic axillary,infrared tympanic with glass-mercury rectal thermometer in infants and young children. J Med Assoc Thai 2000;83(9): 1068-76

5. Shann F, Mackenzie A. Comparison of rectal, axillary and forehead temperatures. Arch Pediatr Adolesc Med 1996;150(1):74-8

6. Lacoumenta S, Hall GM. Lquid crystal thermometry during anaesthesia. Anaesthesia 1984;39 (1):546

7. Board M. Comparison of disposable and glass rnercury thermometesr. Nurs Times 1995;91(33): 36-7 